\title{
A PATIENT WITH POLYTRAUMA INCLUDING A SEVERE HEAD INJURY, HAEMOTHORAX AND CARDIAC TAMPONADE
}

\author{
Bhagya Gunetilleke* \\ Senior Registrar in Anaesthetics, Neurosurgical Intensive Care Unit, \\ National Hospital of Sri Lanka, Colombo \\ *Corresponding author: bhagya.gun@gmail.com
}

Key words: intracranial pressure

Accidental injury causes over 3 million deaths worldwide annually. It is the second most common cause of death in all age groups and the leading cause of death in adults younger than 45years in the United Kingdom ${ }^{(1)}$.

Among the causes of deaths due to trauma, motor vehicle crashes account for a majority, often accounting for as much as $70 \%$ of deaths ${ }^{(2)}$.

Death due to injury occurs in three peaks on a time scale. Necessarily fatal injuries such as aortic transection gives rise to the first peak occurring within seconds to minutes of the incident.

The second peak follows within a few hours and as in this patient maybe caused by hemopneumothoraces and significant blood loss due to multiple injuries.

A third peak caused by sepsis and multiple organ dysfunction follows in the days to weeks following the incident.

The severity and extent of primary brain injury as well as the secondary brain injury are major determinants of outcome.

Damage to neuro-vascular elements, deranged autoregulation of cerebral blood flow with resistant vasospasm, loss of $\mathrm{CO}_{2}$ reactivity, excitotoxicity with uncoupling of blood flow and metabolism, intracranial hypertension and neuronal ischaemia ultimately lead to cell necrosis, apoptosis and scar formation.

The management of severe multiple injuries is based on established trauma care guidelines such as Primary trauma care (PTC) or Advanced Trauma Life Support (ATLS) ${ }^{(2)}$.
Mr S.S.C.A.W, is a 42 year old. An unrestrained driver of a motor car. He was involved in a head on collision with a lorry at a combined speed of approximately $100 \mathrm{~km} / \mathrm{h}$ and was admitted with multiple severe injuries to a base hospital at 10am and was subsequently transferred to the National Hospital of Sri Lanka.

Since the Glasgow coma score was 8 on admission, the patient was intubated and ventilated prior to transfer.

Anterior \& posterior nasal packs had been inserted to control severe epistaxis.

Details of medical conditions, allergies, last meal were not documented and were unavailable.

Respiratory, cardiovascular, neurological parameters had not been documented upto the time of admission to the accident service, National Hospital of Sri Lanka.

A primary survey was conducted on admission to the resuscitation room at $12: 12 \mathrm{pm}$.

Severe maxillo-facial trauma with bleeding was noted.

The cervical spine which was not stabilized during transfer was secured with a rigid cervical collar.

Spontaneous respiratory efforts were noted.

Chest drains were inserted as bilateral haemothoraces were suspected. 200-300ml of blood was drained from each chest drain immediately after placement.

Diffuse crepitations were audible in both lungs. Pulse oximetry was $100 \%$ on $\mathrm{FiO}_{2}$ 1.0. 
Bleeding from multiple sites on the chest and scalp was noted.

A pulse rate of 102 / minute, capillary refill time of $>2$ seconds and a blood pressure of $96 / 50 \mathrm{mmHg}$ were suggestive of haemodynamic instability.

14 gauge cannulae had been inserted on both upper limbs. Blood was obtained for grouping and crossmatch and an infusion of normal saline infusion commenced.

A complete neurological examination was not possible due to sedation and paralysis. Despite periorbital edema examination of pupils revealed a $5 \mathrm{~mm}$ non reacting pupil on the right and a $3 \mathrm{~mm}$ reactive pupil on the left.

Exposure revealed multiple lacerations on the body.

A urinary catheter was inserted and clear urine was noted.

$\mathrm{X}$ rays of the chest, cervical spine, pelvis upper \& lower limbs were obtained.

A CT scan of the brain revealed bilateral frontal haemorrhagic contusions, a right sided temporoparietal haematoma, cerebral edema with a midline shift \& a base of skull fracture.

A decision was made to proceed with neurosurgery if the patient was haemodynamically stable.

The patient continued to be haemodynamically unstable with a fluctuating heart rate and hypotension and was transferred to the Neuro Surgical Intensive Care Unit (NSICU) at 2.00pm.

On admission to the NSICU the primary survey was repeated as the patient was unstable.

The airway was secure and the cervical spine immobilized as a cervical spinal injury could not be excluded.

The patient was being ventilated in volume control mode with a $\mathrm{FiO}_{2}$ of 1.0

Multiple puncture marks were noted on the anterior chest wall possibly due to impact with the steering wheel and dashboard.
Air entry was reduced bilaterally with both chest drains draining more than $600 \mathrm{ml}$ each from the time of insertion.

On examination of the chest X-ray diffuse opacities and a widened mediastinum were noted. These features together with the fact that the patient remained hemodynamically unstable with transient responses to fluid boluses pointed to a mediastinal injury with haemorrhage; such as an aortic dissection or cardiac tamponade.

A request for an urgent 2 dimensional echo was turned down.

An ultrasound scan of the abdomen including a subcostal view of the pericardium failed to reveal a pericardial effusion or cardiac tamponade.

A cardiothoracic surgical opinion was sought. An urgent contrast enhanced $\mathrm{CT}$ scan of the chest was requested to exclude an aortic injury.

Despite the haemodynamic instability the patient was transferred for a CT scan. The scan revealed a significant fluid collection in the pericardial sac with bilateral pleural effusions.

The patient suffered a bradycardic/ asystolic cardiac arrest while in the CT scanner, but was successfully resuscitated with 2 cycles of cardiopulmonary resuscitation and intravenous fluids.

The patient was rushed to the cardiothoracic operating theatre for a sternotomy and exploration.

General anaesthesia was induced with $1 \mathrm{mg}$ of midazolam, 50 micrograms of fentanyl \& $4 \mathrm{mg}$ of pancuronium.

Repeated arterial blood gases revealed severe hypoxia, hypercapnia and metabolic acidosis.

The patient remained hemodynamically unstable despite the transfusion of 5 units of packed red cells, 4 units of fresh frozen plasma, 4 units of platelet concentrate.

The pupillary reactions could not be assessed due to severe periorbital edema.

The sternotomy revealed $200 \mathrm{ml}$ of pericardial fluid and bilateral haemothoraces with approximately $1000 \mathrm{ml}$ on each side. 
Lacerations of both internal mammary arteries, innominate veins and dehiscence of the manubriosternal junction were noted.

As the sternotomy was being closed the patient suffered an asystolic cardiac arrest from which he could not be resuscitated despite initiation of advanced life support.

\section{Discussion}

The patient with multiple injuries requires an initial assessment which includes a primary survey and resuscitation. This is followed by a secondary survey and definitive care.

Airway maintenance with protection of the cervical spine

This patient required intubation as his airway was at risk due to the extensive maxillo-facial injuries and a severe head injury with a Glasgow coma score (GCS) of 8. In addition this patient required assisted ventilation in view of the chest injuries and to prevent secondary damage to the injured brain.

Being a victim of a high velocity motor vehicle accident and the presence of injuries to the head and chest are risk factors for spinal cord injuries.

$5 \%$ of patients with head injuries have an associated spinal injury while $10 \%$ of patients with a cervical spine fracture have a second noncontiguous vertebral column fracture ${ }^{(2)}$.

In a patient who is comatose the spinal cord is immobilized with a cervical collar, sand bags on either side of the head and a tape across the forehead and a spine board until a spinal cord injury can be safely excluded ${ }^{(3)}$. A spinal cord injury can be reliably excluded following CT scan of the spine from $\mathrm{C} 1$ to $\mathrm{T} 1$ with 3 dimensional reconstruction by a competent radiologist or a magnetic resource imaging if the CT scan is inconclusive. Plain x-rays are considered inadequate to clear the cervical spine of an obtunded patient ${ }^{(3)}$.

In this patient with a potential spinal cord injury the airway should have been secured by a rapid sequence induction with cricoid pressure to prevent aspiration and manual in-line stabilization followed by placement of a rigid cervical collar to protect the spinal cord. Log rolling should have been employed when moving the patient.

This patient was transferred after intubation but a rigid cervical collar was placed only on admission to the National Hospital of Sri Lanka (NHSL). Details of the technique of intubation were not available.

\section{Breathing and Ventilation}

The deceleration injury due to impact with the steering wheel increases the risk of rib fractures, pulmonary contusions, pneumothoraces and haemothoraces.

The presence of a severe head injury mandates controlled ventilation to ensure adequate oxygenation and normocapnea.

The goals of ventilation in Intensive Care Unit (ICU) were a $\mathrm{PaO}_{2}>100 \mathrm{mmHg}$ and $\mathrm{PaCO}_{2} 35$ $40 \mathrm{mmHg}$ to minimise secondary brain injury.

Pre-admission hypoxaemia and hypotension are associated with a poor prognosis.

During the primary survey on admission to the NHSL a puncture wound on the right anterior parasternal region and bilaterally reduced air entry were noted. Intercostal tubes were inserted as pneumothoraces/ haemothoraces were suspected.

The patient remained haemodynamically unstable and intercostal tube drainage continued at more than $150 \mathrm{ml} /$ hour.

A chest X-ray revealed bilateral pleural effusions and a widened mediastinum.

Though generally a haemodynamically unstable patient should not be placed in a CT scanner, this patient underwent $\mathrm{CT}$ scanning as it was felt a CT scan would reveal useful information to guide further management.

The CT scan revealed a pericardial effusion and bilateral pleural effusions but did not reveal an aortic dissection.

The patient suffered a non VF/non VT cardiac arrest within the radiology suite but responded promptly to cardiopulmonary resuscitation, adrenaline, atropine and iv fluids.

A pericardiocentesis was attempted without success.

The patient was rushed for an emergency thoracotomy.

Circulation and control of haemorrhage 
Persistent hypotension in brain injured patients is a poor prognostic indicator and upto $50 \%$ of preventable deaths of head injured patients is due to uncontrolled haemorrhage and inadequate resuscitation $^{(4)}$.

The aim is to maintain a cerebral perfusion pressure greater than $70 \mathrm{mmHg}$. In the absence of intracranial pressure monitoring, a mean arterial pressure considerably above that represented by a systolic blood pressure of $90 \mathrm{mmHg}$ is recommended ${ }^{(5)}$.

This could not be achieved due to the ongoing blood loss and cardiac dysfunction due to tamponade.

Transfusion of packed red cells has been shown to correlate with poor outcome ${ }^{(6)}$.

Disability and Neurological assessment

CT scan of the head is the radiological investigation of choice in patients with Traumatic Brain Injury (TBI) and should ideally be combined with a scan of the spine upto T1 to identify any injuries to the cervical spine ${ }^{(1)}$.

This patient being a young male, an occupant of a vehicle as opposed to a pedestrian and the absence of penetrating brain injury were factors pointing to a good outcome despite the presence of a severe $\mathrm{TBI}^{(5)}$.

Bilaterally unreactive pupils are associated with a poor outcome in $70-90 \%$ compared with a poor outcome in $30 \%$ of those with bilaterally reactive pupils. The outcome in patients such as this, with unilaterally reactive pupils is in between these figures and in $30 \%$ is associated with an operable lesion ${ }^{(1)}$.

However the GCS of 8 , the presence of a midline shift, compression of basal cisterns and a traumatic subarachnoid haemorrhage were poor prognostic factors ${ }^{(1)}$. Based on the Marshall classification of the CT findings this patient was a diffuse injury category III which indicated a poor outcome.

The occurrence of hypotension, hypoxia and hypercapnia as in this patient at any point following injury, during resuscitation or intraoperatively is associated with increased mortality ${ }^{(1)}$.

Table 7 Marshall CT classification of TBI

\begin{tabular}{|l|l|}
\hline Category & Definition \\
\hline Diffuse injury I (no visible pathology) & $\begin{array}{l}\text { No visible intra-cranial pathology seen on CT } \\
\text { scan }\end{array}$ \\
\hline Diffuse injury II & $\begin{array}{l}\text { Cisterns are present with midline shift < 5 } \\
\text { mm and/or lesion densities present } \\
\text { No high-or mixed-density lesion }>\text { ml, } \\
\text { may include bone fragments and foreign } \\
\text { bodies }\end{array}$ \\
\hline Diffuse injury III & $\begin{array}{l}\text { Cisterns compressed or absent with mid-line } \\
\text { shift } 0-5 \mathrm{~mm} \\
\text { No high-or mixed-density lesion }>25 \mathrm{ml}\end{array}$ \\
\hline Diffuse injury IV & $\begin{array}{l}\text { Mid-line shift }>5 \text { mm } \\
\text { No high or mixed density lesion }>25 \mathrm{ml}\end{array}$ \\
\hline Evacuated mass lesion & Any lesion surgically evacuated \\
\hline Non - evacuated mass lesion & $\begin{array}{l}\text { High - or mixed - density lesion }>25 \mathrm{ml}, \text { not } \\
\text { surgically evacuated }\end{array}$ \\
\hline
\end{tabular}




\begin{tabular}{|c|c|c|c|c|c|}
\hline Category & Outcome $^{94}$ & & Frequancy & & \\
\hline & $\begin{array}{l}\begin{array}{l}\text { Unfavourable } \\
\text { (dead }\end{array} \\
\text { vegetative, } \\
\text { severe } \\
\text { disability) }\end{array}$ & $\begin{array}{l}\text { Favourable } \\
\text { (mid disability, } \\
\text { good recovery) }\end{array}$ & TCDB $^{94}$ & $\begin{array}{l}\text { European } \\
\text { Nimodipine } \\
\text { Trial64 }\end{array}$ & EBIC survey \\
\hline $\begin{array}{l}\text { Diffuse injury I } \\
\text { (no visible } \\
\text { pathology) }\end{array}$ & 38 & 62 & 7 & 8 & 12 \\
\hline Diffuse injury II & 65 & 35 & 24 & 33 & 28 \\
\hline Diffuse injury III & 84 & 16 & 21 & 11 & 10 \\
\hline Diffuse injury IV & 94 & 6 & 4 & 4 & 2 \\
\hline $\begin{array}{l}\text { Evacuated mass } \\
\text { lesion }\end{array}$ & 77 & 23 & 37 & 38 & 48 \\
\hline $\begin{array}{l}\text { Non - Evacuated } \\
\text { mass lesion }\end{array}$ & 89 & 11 & 5 & 4 & - \\
\hline
\end{tabular}

Management of head injury

Severe TBI classified as a GCS $<9$, carries a poor prognosis. The mortality in severe brain injury is approximately $25 \%$ with only $20 \%$ recovering with a good outcome.

Prompt specialist medical and surgical management and protocolized treatment in a specialized neuro critical care unit improves outcome in severe traumatic brain injury with the reduction in mortality to less than $25 \%{ }^{(5)}$.

The injured brain may be hypoperfused by upto $50 \%$ in addition to the loss of autoregulation of cerebral blood flow. Since hypocapnea causes vasoconstriction, hyperventilation to a $\mathrm{PaCO}_{2}$ less than $4.5 \mathrm{kPa}$ is avoided except as a temporary measure in impending tentorial herniation ${ }^{(3)}$. $\mathrm{PaCO}_{2}$ less than $4 \mathrm{kPa}$ has been shown to worsen outcome $^{(1)}$.

A $\mathrm{PaCO}_{2}$ 4.5-5.0 $\mathrm{kPa}(33.7-37.5 \mathrm{mmHg})$ and an $\mathrm{SpO}_{2}>95 \%$ or $\mathrm{PaO}_{2}>10 \mathrm{kPa}(75 \mathrm{mmHg})$ are recommended for patients with $\mathrm{TBI}^{(1)}$.

This patient was paralysed and ventilated aiming for $\mathrm{SpO}_{2}>96 \%$ and $\mathrm{PaCO}_{2} 35-40 \mathrm{mmHg}$.
A cerebral perfusion pressure (CPP) of greater than $70 \mathrm{mmHg}$ is ideally maintained. However in the presence of uncontrolled bleeding a lesser CPP (eg. $50 \mathrm{mmHg}$ ) may be accepted in order to avoid dislodging blood clots and to minimise intravenous fluid transfusions and subsequent worsening cerebral edema, hypothermia, coagulopathy and acidosis ${ }^{(1)}$.

Since CPP=Mean arterial pressure (MAP)-ICP, a MAP of $90 \mathrm{mmHg}$ is recommended assuming an ICP of $20 \mathrm{mmHg}$ in the absence of an ICP monitor (1)

Due to the presence of uncontrolled intrathoracic haemorrhage a lower MAP of $70 \mathrm{mmHg}$ was targeted. Intravenous fluids, blood products as well as noradrenaline and dobutamine were used to achieve this target in the intensive care unit as well as in the perioperative period. Hypotension in the perioperative period is associated with a doubling of mortality ${ }^{(1)}$.

Intracranial pressure (ICP) monitoring.

ICP and CPP are independent predictors of outcome. An ICP of $20-25 \mathrm{mmHg}$ is considered the threshold for surgical intervention to control $\mathrm{ICP}^{(65 .}$ Use of ICP guided protocols improve outcome in severe TBI. 
Severe TBI with an abnormal CT scan as in this patient is a definite indication for initiating ICP monitoring.

Patients with space occupying lesions are at a great risk of developing intracranial hypertension especially in the presence of hypoxia or hypotension. ICP monitoring is hence useful in patients such as this as it can be used to guide therapy especially if the patient undergoes extracranial surgery.

\section{Glycaemic control}

Intensive glycaemic control (5.0-6.7mmol/1) though associated with an improved outcome in critically ill patients is found to result in unacceptable levels of hypoglycaemia and damage to neuronal cells when compared to loose control $(6.7-8.3 \mathrm{mmol} / \mathrm{l})^{(1)}$

Glucometer readings obtained on admission and in theatre were 8.0 and $8.8 \mathrm{mmol} / \mathrm{l}$ respectively. Active control of blood glucose with insulin was not attempted at this stage.

\section{Seizures}

Increased cerebral metabolic activity and $\mathrm{O}_{2}$ consumption result in secondary brain injury. Phenytoin and carbamazepine prevent early seizures but have no direct impact on outcome ${ }^{(1)}$.

\section{Management of blunt chest trauma}

Many patients such as this with blunt trauma to the chest die after admission to hospital and upto a third of such deaths are preventable. Only 10-15\% require surgical intervention for blunt chest injuries. Aortic injury is the second most common cause of death after head injuries in road traffic accidents $^{(7)}$.

Mediastinal lesions including an aortic dissection and pericardial tamponade were considered and an urgent cardiothoracic and radiology referrals were made.

A transected aorta is usually fatal. An incomplete laceration near the ligamentum arteriosum of the aorta results in a haematoma contained by the adventitia or the mediastinum. Such injuries do not result in hypotension which if present is usually due to bleeding at a separate site ${ }^{(2)}$.

Aortography, transoesophageal echocardiography and helical contrast-enhanced CT are used in identifying aortic dissection. If the CT scan is positive the extent of rupture is determined by aortography ${ }^{(2)}$.

The mechanism of injury, hypotension not responding to fluids, inotropes and vasopressors and the presence of a widened mediastinum on chest $\mathrm{x}$-ray prompted further investigations to identify an aortic injury.

Continuous intercostal tube drainage of 150$200 \mathrm{ml} / \mathrm{h}$ seen in this patient was the indication for thoracic surgical intervention.

The presence of rib fractures, hypoxia, contusion on chest X - ray and the need for a chest drain are predictors for pulmonary contusion which is the commonest life threatening injury in blunt chest trauma $^{(7)}$.

Though this patient was ventilated the inability to use adequate amounts of PEEP due to the hypotension and the need for intravenous fluids including blood products may have resulted in the worsening of the pulmonary contusion.

The presence of a myocardial contusion may have contributed to the hypotension and arrhythmias as such lesions are common in blunt chest trauma.

Timing and extent of extracranial surgery in traumatic brain injury

The timing of extracranial surgery will depend on the severity and the effect of such injury on cerebral perfusion and oxygenation ${ }^{(4)}$. Hypoxaemia and hypotension double the mortality in patients with severe traumatic brain injury.

Delay in craniotomy causes most deaths due to head injury especially in the presence of a traumatic subdural haematoma. These factors need to be considered in deciding the sequence of surgery. 
Clearly in this patient the thoracic injury had an effect on blood pressure and oxygenation and rectifying this was a priority.

As an ultrasound scan of the abdomen did not reveal significant amounts of free fluid, a haemoperitoneum as a cause of hypotension was excluded.

That the patient required an emergency thoracotomy was obvious. Whether he would have benefited from a combined craniotomythoracotomy or a least an ICP monitor prior to thoracotomy are points to be considered. In the case of an expanding intracranial lesion a craniotomy is indicated prior to aortic surgery ${ }^{(7)}$.

Surgical treatment of non-life threatening injuries such as maxillo-facial and long bone fractures can be delayed upto 72 hours as haemodynamic instability associated with such procedures could worsen secondary brain injury ${ }^{(4)}$.
2. Advanced Trauma Life Support For Doctors. Student Course Manual, $7^{\text {th }}$ edition

3. Clearing the cervical spine in the unconscious patient. C.Cairns, P. Harrison Continuing Education in Anaesthesia, Critical care and Pain (2008). Vol 8;no 4:117-120(2008)

4. Anaesthesia for extra-cranial surgery in patients with traumatic brain injury. A.Prabhu, B.Matta Continuing Education in Anaesthesia, Critical care and Pain(2004). Vol4:no5;156-159

5. A.G.Saayman, G.P.Findlay. The management of blunt thoracic trauma. Continuing Education in Anaesthesia, Critical care and Pain (2003). Vol3:no6;171-174

6. Guidelines for the management of severe traumatic brain injury, $3^{\text {rd }}$ Edition. Brain trauma foundation, 2007.

7. Salim A. Role of anaemia in traumatic brain injury. Journal of the American College of Surgeons 2008, 207;5: 656-662

$* * * * * * * * * * * * * * * * * * * * * * * * * * * * * * * * * * * * * * * * * * * * * * * * * * * * * * * * * * * * * * * * * * * * * * * * *$

\section{THE COLLEGE OF ANAESTHESIOLOGISTS OF SRI LANKA}

\section{B S PERERA ORATION}

Applications are hereby called for the "B. S. Perera Oration", to be held on the $23^{\text {rd }}$ January 2010 at the $26^{\text {th }}$ Annual Scientific Sessions of the college.

\section{Terms and Conditions for the Oration.}

1. Five copies of the entire oration should be sent before $31^{\text {st }}$ October 2009 to The Secretary, College of Anaesthesiologists of Sri Lanka and there should not be any substantial alteration in the text when the lecture is finally delivered.

2. The lectureship is open to all members of the College of Anaesthesiologists.

3. Five copies of a brief resume of the salient points of the paper should also be submitted indicating any contribution to further advances in knowledge of the subject.

4. The lecture should preferably not exceed 45 minutes.

5. A committee of five will be nominated by the council to scrutinize papers submitted and to select a suitable candidate. This committee of five shall award the lectureship.

6. The lecture should be related to anaesthesia and intensive care and should be based on the original work of the lecturer.

7. In the event of the committee being unable to select a lecturer from the applicants, they may invite a lecturer of international repute to deliver the lectureship.

8. The honorarium may be in the form of a gold medal.

9. Press should not be invited and photographs and accounts of the lecture should not be published in the Newspapers, without the permission of the College Council.

10. Copyright of the oration belongs to the College of Anaesthesiologists of Sri Lanka. 